\section{Annual Population Survey household data sets}

Top

he Office for National Statistics (ONS)

has developed a version of the Annual

Population Survey (APS) data sets that is specially designed for producing family and household labour market statistics at the subnational level. The new APS household data sets will provide local area statistics on, for example:

- workless households and the people living in them

- couples where both partners are working, one partner is working, neither is working

- employment rates for lone parents and couple parents with dependent children, and for people without dependent children

- children by the economic activity status of their parent(s)

The data sets cover January to December of each year. They contain results from four consecutive quarters of the Labour Force Survey (LFS) and include information from Wave 1 and Wave 5 interviews only. They also include results from the annual local area LFS boosts. Each data set contains information from a sample of around 160,000 households, whereas the existing LFS household data sets are based on a sample of around 53,000 households.

Unlike the main (person-level) APS data sets, people with unknown economic activity status are included. They are given the same weight as other members of their household and their economic activity status is imputed using a 'donor imputation method'. The APS household data sets include all of the variables found on the main APS data sets, except for the earnings variables. They also include additional derived variables for analysing the combined economic activity status of family and household members.

The first APS household data set (for January to December 2007) is due to be released in summer 2008, with a back series covering 2004, 2005 and 2006. An article giving further information about the data sets will be published later this year. ONS plans to publish APS-based family and household statistics for local areas on a regular basis thereafter, depending on customer requirements. Customers will be able to commission bespoke tabulations from the LFS Data Service and to obtain access to the data sets, subject to protocols governing access to survey microdata. Guidance on how to produce family and household analyses will also be available.

\section{Contact}

Annette Walling

(C) 01633455840

annette.walling@ons.gsi.gov.uk

\section{Task Force on the quality of the Labour Force Survey}

s previously reported in the
September 2007 edition of Economic
\& Labour Market Review, the Office for National Statistics (ONS) is participating in a Eurostat (Statistical Office of the European Community) Task Force on the quality of the Labour Force Survey (LFS). The Task Force was set up in spring 2007 and is expected to run for two years, producing a final report around summer 2009. In addition to the UK, experts from Germany, Greece, Spain, France, Italy, the Netherlands, Poland and Portugal are taking part. Non-participating EU countries receive progress reports at the six-monthly Labour Market Statistics Working Groups held at Eurostat, Luxembourg.

The Task Force's remit is to examine issues relating to the quality of the LFS, particularly the estimates of employment and unemployment, with regard to accuracy, coherence and comparability. It is therefore orientated towards examining the practices and methods employed in conducting and compiling the survey across Member States.

The first meeting held in October 2007 concentrated on accuracy, and the sources of error that can arise in survey estimates due to both sampling error and nonsampling error. A wide range of issues and possible solutions were discussed. A key theme emerging was that the experiences of each Member State can be rather different and so prescribing generic solutions across European Union (EU) countries would not necessarily be helpful. Rather, suggestions for best practice would be appropriate. The difficulties with conducting surveys in smaller EU countries as opposed to larger Member States can be very different. Similarly, use of different survey collection modes (face to face interviewing, telephone or internet) generates different degrees of bias across countries, and across regions within Member States, and in part was determined by the rural-urban balance.

The second meeting was held on 6-7 March 2008. It concluded discussions on accuracy, and held initial discussions on the topic of coherence between labour market and national accounts estimates, with ONS presenting its drivers for improving coherence, and experience to date in this area. The next meeting will be held in September 2008.

\section{Contact}

Debra Prestwood

C 01633455882

debra.prestwood@ons.gsi.gov.uk

\section{Labour Force Survey, reweighting and seasonal adjustment review 2008}

rel

he Office for National Statistics (ONS)

monthly Labour Market Statistics First

Release of 14 May 2008 will contain

Labour Force Survey (LFS) aggregate results that are consistent with reweighted LFS microdata. Both the published LFS aggregates and the reweighted LFS microdata, used for detailed analyses, will be in line with the most recently published official population estimates.

Aggregate results in the UK and regional First Releases are key labour market indicators, for example, the levels and rates of employment and unemployment. They are derived from the LFS microdata and are calculated for any period of three consecutive months. These are referred to as three-month rolling averages - averages for January to March, February to April, and so on. The aggregate results are seasonally adjusted.

LFS microdata are quarterly data sets containing all survey questions. They are made publicly available as databases for external users to access and produce their own analyses. They enable more detailed analysis but are published for calendar quarters only and are not seasonally adjusted.

The current microdata sets have been weighted using population estimates published in 2003. Regular updates to these estimates have meant that the LFS microdata have become increasingly out of date. Reweighting of the microdata using the latest population estimates for all calendar quarters back to 1992 is now 
complete. This work incorporated small methodological improvements to the weighting method.

Since 2003, the LFS aggregate results have been interim reweighted every year. Interim reweighting applies adjustments to the aggregate results to reflect how the latest available official population estimates compare with those used for calculating the microdata. This amounts to an approximation of the effect that a full reweighting of the microdata would have. The aggregates were last interim reweighted in October 2007 and reflect the current population estimates.

Since all LFS aggregates have been revised for all periods back to 1992, a large scale evaluation of the seasonality of the aggregates has been conducted, to ensure the most appropriate methods are used in the seasonal adjustment.

From 14 May 2008, reweighted microdata will feed through directly to the published aggregate results. Interim reweighting will not be required until the population estimates are next updated. ONS will publish an article on 14 May 2008 on the National Statistics website which will also appear in the July 2008 edition of Economic \& Labour Market Review. The article will compare the reweighted microdata with the current microdata, and will also describe the extent to which the aggregate results have been revised due to both reweighting and the seasonal adjustment review.

\section{More information}

www.statistics.gov.uk/cci/article.asp?id=1992

\section{Contact}

Nicholas Palmer

6

01633455839

nicholas.palmer@ons.gsi.gov.uk

Matthew Hughes

C 016

matthew.hughes@ons.gsi.gov.uk

\section{8th International}

\section{Conference of Labour} Statisticians: Geneva, November 2008

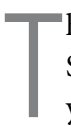

he International Conference of Labour Statisticians takes place every five years and the next one (the 18th) will be held in Geneva between 24 November and 5 December 2008. The Conference will discuss and adopt international statistical standards on two topics, Child Labour and Working Time. The proposal for Working Time has been developed by the 'Paris
Group' (one of a number of 'city groups' set up by the United Nations Statistical Commission) on which the Office for National Statistics (ONS) has been actively represented. An article discussing some of the issues entitled 'Measuring Working Time arrangements' was published in the January 2004 of Labour Market Trends.

The Conference will also discuss and provide guidelines for future international work on the measurement of decent work, indicators of labour underutilisation and statistics on volunteer work. In addition, the Conference will examine its functions, organisation and frequency in response to the recent UN Programme Review of Labour Statistics. This Review, which was undertaken by ONS, recommended that the International Labour Organisation should work with the UN Statistics Division, OECD and Eurostat to improve the process of setting international standards by, for example, reviewing the frequency, duration and agenda setting of International Conference of Labour Statisticians meetings, and extending the use of expert groups to work on topical issues.

\section{More information}

www.ilo.org/global/What_we_do/ Statistics/events/icls/lang--en/index.htm

www.ilo.org/global/What_we_do/ Statistics/events/icls/lang--en/docName-WCMS_092024/index.htm

www.statistics.gov.uk/cci/article. asp? id =683

http://unstats.un.org/unsd/statcom/ doc08/2008-2-employment-e.pdf

\section{Contact}

Graeme Walker

01633455824

graeme.walker@ons.gsi.gov.uk

\section{National Minimum Wage}

0 n 5 March 2008, the Government accepted the Low Pay Commission's recommendations that the adult National Minimum Wage (NMW) rate should rise from $£ 5.52$ to $£ 5.73$ per hour with effect from October 2008. The youth development rate (for 18 to 21 year olds) will rise from $£ 4.60$ to $£ 4.77$ per hour and the minimum wage for 16 and 17 year olds from $£ 3.40$ to $£ 3.53$ per hour.

The Low Pay Commission Report 2008 provides further details on these recommendations, including analysis of the impact of the NMW, its effect on different groups of workers, compliance and enforcement and how the wage rates were set. The report is available to download from the Low Pay Commission's website.

The Office for National Statistics (ONS) publishes estimates of the number of lowpaid jobs, and specifically those paying below the NMW from the Annual Survey of Hours and Earnings in November each year. In spring 2007, 292,000 jobs paid below the NMW rates that were applicable at the time, amounting to 1.2 per cent of all the jobs in the labour market. Further information on low pay estimates is available from the ONS website.

\section{More information}

www.lowpay.gov.uk

www.statistics.gov.uk/statbase/product. asp? vlnk=5837

\section{Contact}

Stephen Hicks

.

01633456899

stephen.hicks@ons.gsi.gov.uk 